\title{
Portal hypertensive colopathy in Egyptian cirrhotic patients: an endoscopic study Helmy Shalaby ${ }^{\mathrm{a}}$, El-Sayed El-Meghawry ${ }^{\mathrm{b}}$, Sabry Al-Azhary ${ }^{\mathrm{b}}$, Khaled Nagy Elfayoumy ${ }^{\mathrm{b}}$, El-Sayed Abo Zeid ${ }^{\mathrm{b}}$
}

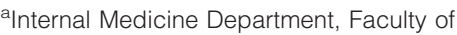
Medicine, Al-Azhar University, Cairo, ' ${ }^{\text {Internal }}$ Medicine Department, Faculty of Medicine, Al-Azhar University, New Damietta, Egypt

Correspondence to Khaled N. Elfayoumy, MD, Al-Azhar University Hospital, New Damietta, 54517, Egypt. Tel: 01003778745; fax: +20 572 404 035; e-mails: kh_elfayoumy@azhar.edu.eg. kh_elfayoumy@yahoo.com
\end{abstract}

Received 18 July 2018

Accepted 31 July 2018

The Egyptian Journal of Internal Medicine 2018, 30:249-254

\begin{abstract}
Background
Hepatitis C virus (HCV) infection is a major health problem in Egypt. It is often complicated by liver cirrhosis and portal hypertension, resulting in gastroesophageal varices, gastropathy, and colopathy. However, there is still lack of data with respect to the prevalence and clinical relevance of colopathy in this kind of liver disease. The aim of this study was to determine the prevalence of colopathic lesions in HCV-related cirrhotic patients, and to study their associations with the severity of liver disease and manifestations of portal hypertension

Patients and methods

This cross-sectional study included 60 patients with liver cirrhosis who were submitted to thorough clinical, laboratory, and ultrasonographic examinations. In addition, both upper and lower gastrointestinal endoscopy were performed to detect portal hypertensive complications including colopathic lesions. According to their severity, colopathic lesions were graded into three grades. Patients with higher colopathic grading (grade 2 and 3 ) were compared with the remaining participants with respect to the severity of the liver disease and other manifestations of portal hypertension.

Results

The prevalence of colopathy in cirrhotic patients with underlying HCV etiology was $91 \%$. Patients with higher grades of colopathy were characterized by more severe liver disease. Moreover, they had increased frequency of both esophageal and gastric varices, and prior sclerotherapy or band ligation, as well as more collaterals and gastropathy, and higher grades of esophageal varices.

Conclusion

Colopathic lesions are frequent in patients with HCV-induced cirrhosis. Getting endoscopic treatment for varices is a risk factor for developing higher grades of colopathy. The latter could be considered as a marker of a worse prognosis in patients with HCV cirrhosis.
\end{abstract}

Keywords:

Child-Pugh scoring, colopathy, hepatitis C virus, liver cirrhosis, portal hypertension

Egypt J Intern Med 30:249-254

(1) 2019 The Egyptian Journal of Internal Medicine

1110-7782

\section{Introduction}

Viral hepatitis has been identified as the seventh leading cause of mortality worldwide [1]. Of these, hepatitis $\mathrm{C}$ virus $(\mathrm{HCV})$ is estimated to be responsible for nearly half of this mortality owing to its adverse effects on the liver and portal circulation [2]. Therefore, HCV constitutes a major challenge to Egypt as it has the highest prevalence globally $[3,4]$.

Portal hypertension with its sequelae (esophagus and gastric varices) is responsible for the majority of cases of gastrointestinal hemorrhage in those kinds of patients [5]. Moreover, portal hypertension was thought to cause hemodynamic and mucosal changes in the entire gut resulting in gastropathy and colopathy. Both disorders are important clinically because they may lead to gastrointestinal bleeding [6]. Anyway, this type of bleeding is less dramatic than that caused by upper gastrointestinal etiologies [7].

Nevertheless, Hosking et al. [8] recommended performing colonoscopy for cirrhotic patients aiming to assess the portal hypertension-related lesions in the colorectal region.

Despite several studies in the last two decades, a lot of controversies is still present with respect to diagnostic criteria and prevalence of colopathy [9]. To the best of our knowledge, no studies have addressed this

This is an open access journal, and articles are distributed under the terms of the Creative Commons Attribution-NonCommercial-ShareAlike 4.0 License, which allows others to remix, tweak, and build upon the work non-commercially, as long as appropriate credit is given and the new creations are licensed under the identical terms. 
condition in patients with HCV-related cirrhosis. This provides a real challenge to the management of that kind of colonic pathology.

The objectives of the current study were to define the prevalence of colopathic lesions in HCV-related cirrhotic patients and to relate the severity of these lesions to the manifestations of portal hypertension and the severity of liver disease.

\section{Patients and methods}

The study was carried out on 60 cirrhotic patients with $\mathrm{HCV}$-induced cirrhosis in Al-Azhar University Hospital (New Damietta). All patients were submitted to full history taking and complete physical examination as well as laboratory, ultrasonographic, and endoscopic evaluation. Presence of other underlying liver etiologies, hemodynamic instability, hepatic encephalopathy of at least grade 2, or coagulopathy refractory to correction constituted the main exclusion criteria.

Diagnosis of cirrhosis was based on the clinical, biochemical, and ultrasonographic criteria [10], whereas the severity of liver disease was assessed in accordance with Child-Pugh's classification into Child's A, B, and C.

Indicators of portal hypertension included clinical and ultrasonographic (splenomegaly, collaterals, ascites, and variceal bleeding); and upper gastrointestinal endoscopic criteria (esophageal varices and portal hypertensive gastropathy); as well as, low platelet counts [11].

\section{Laboratory investigations}

Following overnight fasting, with the use of fully automated chemistry analyzer (Beakman Coulter AU 480), $5 \mathrm{ml}$ of venous blood from each patient were analyzed to determine the complete blood count, liver function tests (serum albumin, serum bilirubin, alanine aminotransferase, aspartate aminotransferase), as well as serum creatinine and fasting blood glucose. Prothrombin time was measured using Diamed $\mathrm{GmbH}$ (Ottobrunn, Germany) and HCV antibodies by specific enzyme linked immunoassay (ULTRA kit, BioMérieux SA, France).

\section{Abdominal ultrasonography}

Second to that, an abdominal ultrasonography was performed using Toshiba Ultrasound the Aplio 500 Platinum Machines (Toshiba Medical Systems Co. Ltd, Otawara, Japan) to determine the liver and splenic size, detect any collaterals, ascites, focal lesions, or signs suggestive of cirrhosis (course heterogonous echopattern, surface nodularity, and caudate lobe hypertrophy) [12], and to assess the collaterals, and portal vein shape, diameter, and flow velocity (using Doppler ultrasonography).

\section{Endoscopy evaluation}

Thereafter, an upper gastrointestinal endoscopy was performed using the PENTAX Medical EPK i5000 video processor (PENTAX Medical, Tokyo, Japan) to evaluate the presence and grading (if any) of esophageal varices, gastric varices, or portal hypertensive gastropathy.

Esophageal varices were detected and graded from 1 to 4 in accordance with de Franchis et al. [13] (grade 1, varices at the level of mucosa; grade 2 , varices smaller than $5 \mathrm{~mm}$ and fulfilling less than $1 / 3$ of the esophageal lumen; grade 3, varices larger than $5 \mathrm{~mm}$ and fulfilling more than $1 / 3$ of the esophageal lumen; grade 4 , varices occupying more than $2 / 3$ of the esophageal lumen). In addition, identification of portal hypertensive gastropathy was done based on the two-category classification system, by Baveno III consensus. This classification denotes mild when the only change consists of a snakeskin mosaic pattern, and is classified as severe when in addition to the mosaic pattern, flat or bulging red or black-brown spots are seen, and/or when there is active hemorrhage [13].

After standard preparation at the night prior to the procedure, colonoscopy was performed at the end. The colon was examined on withdrawal with the washing of any obscured mucosa. Portal hypertensive colopathy was graded according to the classification of Bini et al. [14] into three grades: grade 1 , erythema of the colonic mucosa; grade 2, erythema of the mucosa with a mosaic-like pattern; and grade 3, vascular lesions in the colon including cherry-red spots, telangiectasias, or angiodysplasia-like lesions.

\section{Statistical analysis of data}

The collected data were organized, tabulated, and statistically analyzed using software computer package version 19 (SPSS Inc., Chicago, Illinois, USA). For qualitative data, the frequency was calculated, and for comparison between groups of high-grade colopathy with those without (or having only grade 1 ), the $\chi^{2}$-test was used. For quantitative data, mean and SD were calculated and for comparison between groups, independent $t$-test and one-way analysis of variance were performed, each when appropriate. Significance was considered at $P$ value less than 0.05 . 


\section{Ethical approval}

Informed consent was obtained from each patient, and the study was performed in accordance with the principles of the Declaration of Helsinki.

\section{Results}

\section{Clinical characteristics and endoscopic findings}

The study included 60 patients with HCV-related liver cirrhosis, men constituted $75 \%$ of them. The ages of the enrolled patients ranged from 30 to 69 years with mean age $52.3 \pm 6.1$ years. A total of 31 patients were identified to have the class $\mathrm{C}$ Child-Pugh classification, and 39 participants had been previously submitted to endoscopic treatment for esophageal varices in the form of sclerotherapy and/ or band ligation (Table 1).

Esophageal varices were detected in $75 \%$ of the studied population, and grade 3 was the most frequent esophageal varices. The prevalence of gastric varices, however, was much lower (23.3\%). Concerning portal hypertensive gastropathy, a total of 55 cases were diagnosed, with two-thirds of them having the mild form. Also, various types of colopathic lesions were diagnosed in 55 (91\%) cases. A total of 17 cases had grade 1 colopathy, 23 had grade 2 , but only 15 patients were shown to have grade 3 (Table 2).

Table 1 Clinical characteristics and laboratory data of the study population $(n=60)$

\begin{tabular}{|c|c|}
\hline & Mean \pm SD \\
\hline Age (years) & $\begin{array}{l}52.31 \\
\pm 6.12\end{array}$ \\
\hline Sex (male/female) $(n)$ & $45 / 15$ \\
\hline History of hematemesis and/or melena [n (\%)] & 30 \\
\hline $\begin{array}{l}\text { Prior endoscopic treatment of esophageal varices } \\
\text { (sclerotherapy and/or band ligation) }[n(\%)]\end{array}$ & 39 \\
\hline \multicolumn{2}{|l|}{ Child-Pugh classification $[n(\%)]$} \\
\hline A & 12 \\
\hline B & 17 \\
\hline $\mathrm{C}$ & 31 \\
\hline Hemoglobin (g/dl) & $\begin{array}{l}11.57 \\
\pm 1.86\end{array}$ \\
\hline Platelets $\left(\times 10^{3} / \mathrm{mm}^{3}\right)$ & $\begin{array}{l}87.68 \\
\pm 42.71\end{array}$ \\
\hline Bilirubin (mg/dl) & $2 \pm 0.89$ \\
\hline ALT & $\begin{array}{l}43.88 \\
\pm 18.58\end{array}$ \\
\hline AST & $\begin{array}{l}48.13 \\
\pm 24.09\end{array}$ \\
\hline Albumin (g/dl) & $2.76 \pm 0.33$ \\
\hline INR & $1.47 \pm 0.44$ \\
\hline Creatinine (mg/dl) & $0.9 \pm 0.37$ \\
\hline Fasting blood glucose (mg/dl) & $\begin{array}{r}107.0 \\
\pm 32.11\end{array}$ \\
\hline
\end{tabular}

ALT, alanine transaminase ( $N \leq 45 \mathrm{IU} / \mathrm{l})$; AST, aspartate transaminase $(N \leq 40 \mathrm{IU} / \mathrm{I})$; INR, international normalized ratio.
Associations between colopathy and signs of portal hypertension or Child-Pugh scoring

A group of 30 patients with the previous history of upper gastrointestinal bleeding, all had evidence of colopathy. In addition, 90\% of them had higher grades of colopathy (Table 3 ).

In contrast, $92 \%$ of the patients with either grade 2 or 3 colopathy were having esophageal varices. They were all of Child $\mathrm{B}$ or $\mathrm{C}$ scoring. Higher grades of esophageal varices (grade 3 and 4) constituted nearly two-thirds of all varices in that group (Table 3 ). In addition, 4/5 of this group had received previous sclerotherapy or band ligation for esophageal varices (Table 3).

In contrast, $50 \%$ of patients either with grade 1 (or without) colopathy were lying under Child A classification. Esophageal varices were less prevalent than in the previous group as well as the prior history of sclerotherapy and/or band ligation for esophageal varices $(P<0.001$ for both). Our results showed a close association between the severe form of portal hypertensive gastropathy and the higher grades of colopathy $(P=0.005)$ (Table 3$)$.

Using one-way analysis of variance for comparison of cases without colopathy with each grading category of

Table 2 Ultrasound and endoscopic findings of the study population

\begin{tabular}{lc}
\hline & $N$ \\
\hline Ascites & \\
Absent & 13 \\
Mild & 17 \\
Moderate & 21 \\
Marked & 9 \\
Splenic size (mean \pm SD) & $15.90 \pm 2.38$ \\
PVD (mean \pm SD) & $13.48 \pm 1.92$ \\
PV velocity (mean \pm SD) & $12.50 \pm 2.47$ \\
Collaterals & 33 \\
Gastric varices & 14 \\
Esophageal varices grading & \\
1 & 4 \\
2 & 15 \\
3 & 19 \\
4 & 7 \\
PHG grading & \\
Mild & 36 \\
Severe & 19 \\
PHC grading & \\
1 & 17 \\
2 & 23 \\
3 & 15 \\
\hline
\end{tabular}

PHC, portal hypertensive colopathy; PHG, portal hypertensive gastropathy; PVD, portal vein diameter. 
Table 3 Relation between patients with high grades of colopathy $(2,3)$ and patients with grade 1 or without colopathy

\begin{tabular}{|c|c|c|c|c|}
\hline & \multicolumn{2}{|c|}{ PHC grading } & \multirow[t]{2}{*}{$\chi^{2}$} & \multirow[t]{2}{*}{$P$} \\
\hline & None or one $(n=22)$ & Two or three $(n=38)$ & & \\
\hline History of hematemesis and/or melena & 3 & 27 & 18.37 & $<0.001$ \\
\hline History of sclerotherapy or band ligation & 8 & 31 & 12.52 & $<0.001$ \\
\hline \multicolumn{5}{|l|}{ Child-Pugh classification } \\
\hline A & 11 & 1 & 20.02 & $<0.001$ \\
\hline B & 5 & 12 & & \\
\hline $\mathrm{C}$ & 6 & 25 & & \\
\hline History of lower gastrointestinal tract bleeding (present/absent) & $5 / 17$ & $31 / 7$ & 20.1 & 0.001 \\
\hline Collaterals & 8 & 25 & 4.87 & 0.027 \\
\hline Esophageal varices (total) & 10 & 35 & 16.17 & $<0.001$ \\
\hline \multicolumn{5}{|l|}{ The degree of esophageal varices } \\
\hline One & 1 & 3 & 17.51 & 0.002 \\
\hline Two & 5 & 10 & & \\
\hline Three & 3 & 16 & & \\
\hline Four & 1 & 6 & & \\
\hline Gastric varices & 3 & 11 & 1.82 & 0.176612 \\
\hline \multicolumn{5}{|l|}{ PHG } \\
\hline Mild & 16 & 20 & 10.57 & 0.005 \\
\hline Severe & 2 & 17 & & \\
\hline
\end{tabular}

PHC, portal hypertensive colopathy; PHG, portal hypertensive gastropathy.

Table 4 Comparison between different grades of portal hypertensive colopathy with respect to some indicators of portal hypertension and severity of liver disease

\begin{tabular}{lccccc}
\hline & \multicolumn{3}{c}{ PHC } & \\
\cline { 2 - 5 } & None $(n=5)$ & One $(n=17)$ & Two $(n=23)$ & Three $(n=15)$ & 0.025 \\
\hline Splenic size $(\mathrm{cm})$ & $14.08 \pm 1.54$ & $15.01 \pm 2.68$ & $16.23 \pm 1.71$ & $17.02 \pm 2.59$ & 0.11 \\
PVD $(\mathrm{mm})$ & $12.14 \pm 2.07$ & $12.87 \pm 1.76$ & $13.75 \pm 1.45$ & $14.13 \pm 2.61$ & 0.06 \\
PV velocity $(\mathrm{cm} / \mathrm{s})$ & $14.64 \pm 2.25$ & $13.17 \pm 2.31$ & $11.71 \pm 1.69$ & $12.23 \pm 3.23$ & $<0.001$ \\
Platelets $\left(\times 10^{3} / \mathrm{mm}^{3}\right)$ & $142.60 \pm 44.51$ & $114.82 \pm 46.57$ & $70.91 \pm 20.60$ & $64.33 \pm 30.94$ & 0.03 \\
INR & $1.08 \pm 0.13$ & $1.39 \pm 0.46$ & $1.47 \pm 0.42$ & $1.70 \pm 0.40$ & \\
\hline
\end{tabular}

INR, international normalized ratio; PHC, portal hypertensive colopathy; PV, portal vein; PVD, portal vein diameter.

it, we found significant increase in splenic size $(P=0.025)$, international normalized ratio $(P=0.03)$, with decrease in platelet counts $(P<0.001)$, and a trend towards decrease in portal vein velocity $(P=0.06)$ in cases with higher grades of colopathy (Table 4).

\section{Discussion}

The current work acknowledged the high prevalence of colopathic lesions (91.7\%) in patients with HCVinduced cirrhosis. In literature studies, the prevalence of colopathy among patients with cirrhosis varies widely from $25 \%$ to more than $80 \%$ [15-18].

This variability is potentially understood in the context of the absence of consensus on the classification system of colopathic lesions to date, and this seems to challenge the comparison between studies [6].

Furthermore, the prevalence of colopathy might be underestimated when the patients present with milder forms, such as colitis-like changes or nonspecific vascular lesions. Also, some studies investigated patients on the basis of the absence of esophageal varices [18]. Moreover, we might have included patients with more severe liver disease in our study than the other studies.

With respect to the association between colopathy and the severity of liver disease, previous studies also revealed conflicting results. Several reports confirmed this association [19-22]. Whereas, others failed to confirm such relation [9,23-25]. Some of the latter studies included a large proportion of patients with mild liver disease and this seems to impact their results. In our study, however, advanced colopathic grading was associated with the more severe liver disease as estimated by Child-Pugh scoring. Thus, worsening of the hepatic functions are expected to be associated with more hemodynamic dysfunction and consequently colopathic lesions [21].

Concerning the relationship between colopathy and the degree of portal hypertension, previous reports 
showed great controversies too. In one study, colopathy has been associated with higher portal pressure [20]. Another study related colopathy with more severe esophageal varices and low platelet count [26]. The recent case report of Murphy et al. [27] related hypertensive colopathy presented with severe lower gastrointestinal bleeding and severe anemia to a severe alcoholic liver disease. In that case, the bleeding did not stop except after urgent transjugular intrahepatic portosystemic shunt. In consistent with that, Jeon and Kim [28] linked all the complications of portal hypertension all together including the entity of portal hypertensive enteropathy [29].

In contrast, other studies found no association between colopathy and portal pressure [23], or esophageal varices [24].

In the current study, higher degrees of colopathic lesions were associated with more collaterals, more (and higher grades of) esophageal varices, more severe portal hypertensive gastropathy, as well as more gastric varices, splenic size, and lower platelet counts. All indicated more portal hypertension. Whether this indicates a direct link between the severity of the latter and colopathy or impacted by the presence of a large group of patients with severe liver disease (all were of HCV etiology) remains unclarified.

Results of the current study demonstrated that higher grades of colopathy are more frequent in those who had previously received endoscopic management of esophageal varices in the form of band ligation or sclerotherapy. The resulting variceal obliteration redistributes the blood flow through the portal system. As a consequence, the pressure in the colonic mucosa increases, resulting in the formation of colopathic lesions [28,30]. This could also potentially explain the high prevalence of gastropathy in our study [31]. In this case, it has been suggested that the use of $\beta$-blockers would protect against gastropathic and colopathic changes [32].

Standardized therapeutic guidelines for colopathic lesions still not exist. The use of octreotide [33], or the more invasive transjugular intrahepatic portosystemic shunt procedures may represent future hope for symptomatic patients with that kind of lesions [27].

The main limitation of our study came from the high prevalence of patients with Child-Pugh C scores.

\section{Conclusion}

The current study highlighted highly prevalent colopathy in patients with $\mathrm{HCV}$-related cirrhosis. The presence of high grading colopathic lesions was associated with advanced liver disease and manifestations of portal hypertension and was more frequent in patients with previous endoscopic treatment of esophageal varices. Therefore, the finding of high-grade colopathy could be considered as a marker of a worse prognosis in patients with that kind of infection.

\section{Acknowledgements}

Helmy Shalaby contributed for concept of the study, critical revision of the manuscript. E1-Sayed El-Meghawry contributed for design of the study, critical revision of the manuscript. Sabry Al-Azhary contributed for procedural work, interpretation of data. Khaled N. Elfayoumy contributed for interpretation and analysis of data, drafting and critical revision of the manuscript. El-Sayed A. Zeid contributed for acquisition of data.

\section{Financial support and sponsorship}

Nil.

\section{Conflicts of interest}

There are no conflicts of interest.

\section{References}

1 Stanaway JD, Flaxman AD, Naghavi M, Fitzmaurice C, Vos T, Abubakar I, et al. The global burden of viral hepatitis from 1990 to 2013: findings from the Global Burden of Disease Study 2013. Lancet 2016; 388:1081-1088.

2 Mohd Hanafiah K, Groeger J, Flaxman AD, Wiersma ST. Global epidemiology of hepatitis $C$ virus infection: new estimates of age-specific antibody to $\mathrm{HCV}$ seroprevalence. Hepatology 2013; 57:1333-1342.

3 Hajarizadeh B, Grebely J, Dore GJ. Epidemiology and natural history of HCV infection. Nat Rev Gastroenterol Hepatol 2013; 10:553-562.

4 Ministry of Health and Population [Egypt], El-Zanaty and Associates [Egypt] \& and ICF International. Egypt Health Issues Survey 2015. (Cairo, Egypt and Rockville, Maryland, USA: Ministry of Health and Population and ICF International, 2015). https://dhsprogram.com/pubs/pdf/FR313/FR313.pdf. [Last accessed 2017 Jul 1].

5 Gostout CJ, Viggiano TR, Balm RK. Acute gastrointestinal bleeding from portal hypertensive gastropathy: prevalence and clinical features. Am $J$ Gastroenterol 1993; 88:2030-2033.

6 Urrunaga $\mathrm{NH}$, Rockey DC. Portal hypertensive gastropathy and colopathy. Clin Liver Dis 2014; 18:389-406.

7 Barnert J, Messmann $\mathrm{H}$. Diagnosis and management of lower gastrointestinal bleeding. Nat Rev Gastroenterol Hepatol 2009; 6:637.

8 Hosking SW, Smart HL, Johnson AG, Triger DR. Anorectal varices, haemorrhoids, and portal hypertension. Lancet 1989; 1:349-352.

9 Bresci G, Parisi G, Capria A. Clinical relevance of colonic lesions in cirrhotic patients with portal hypertension. Endoscopy 2006; 38:830-835.

10 Gomez EV, Rodriguez YS, Bertot LC, Gonzalez AT, Perez YM, Soler EA, et al. The natural history of compensated HCV-related cirrhosis: a prospective long-term study. J Hepatol 2013; 58:434-444.

11 Gatta A, Sacerdoti D, Bolognesi M, Merkel C. Portal hypertension: state of the art. Ital J Gastroenterol Hepatol 1999; 31:326-345.

12 Lefton HB, Rosa A, Cohen M. Diagnosis and epidemiology of cirrhosis. Med Clin North Am 2009; 93:787-799. 
13 De Franchis R. Updating consensus in portal hypertension: report of the Baveno III Consensus Workshop on definitions, methodology and therapeutic strategies in portal hypertension. J Hepatol 2000; 33:846-852.

14 Bini EJ, Lascarides CE, Micale PL, Weinshel EH. Mucosal abnormalities of the colon in patients with portal hypertension: an endoscopic study. Gastrointest Endosc 2000; 52:511-516.

15 Naveau S, Bedossa P, Poynard T, Mory B, Chaput JC. Portal hypertensive colopathy. A new entity. Dig Dis Sci 1991; 36:1774-1781.

16 Kozarek RA, Botoman VA, Bredfeldt JE, Roach JM, Patterson DJ, Ball TJ. Portal colopathy: prospective study of colonoscopy in patients with portal hypertension. Gastroenterology 1991; 101:1192-1197.

17 Misra SP, Dwivedi M, Misra V. Prevalence and factors influencing hemorrhoids, anorectal varices, and colopathy in patients with portal hypertension. Endoscopy 1996; 28:340-345.

18 Guimaraes RA, Perazzo H, Machado L, Terra C, Perez RM, Figueiredo FA. Prevalence, variability, and outcomes in portal hypertensive colopathy: a study in patients with cirrhosis and paired controls. Gastrointest Endosc 2015; 82:469-476.

19 Ito K, Shiraki K, Sakai T, Yoshimura H, Nakano T. Portal hypertensive colopathy in patients with liver cirrhosis. World J Gastroenterol 2005; 11:3127-3130.

20 Diaz-Sanchez A, Nuñez-Martinez O, Gonzalez-Asanza C, Matilla A, Merino $\mathrm{B}$, Rincon $\mathrm{D}$, et al. Portal hypertensive colopathy is associated with portal hypertension severity in cirrhotic patients. World J Gastroenterol 2009; 15:4781-4787.

21 Gad $Y Z$, Zeid AA. Portal hypertensive colopathy and haematochezia in cirrhotic patients: an endoscopic study. Arab J Gastroenterol 2011; 12:184-188.

22 Yamakado S, Kanazawa H, Kobayashi M. Portal hypertensive colopathy: endoscopic findings and the relation to portal pressure. Intern Med 1995; 34:153-157.
23 Chen LS, Lin HC, Lee FY, Hou MC, Lee SD. Portal hypertensive colopathy in patients with cirrhosis. Scand J Gastroenterol 1996; 31:490-494.

24 Misra SP, Dwivedi M, Misra V, Dharmani S, Kunwar BK, Arora JS. Colonic changes in patients with cirrhosis and in patients with extrahepatic portal vein obstruction. Endoscopy 2005; 37:454-459.

25 Kamath PS, Wiesner RH, Malinchoc M, Kremers W, Therneau TM, Kosberg $\mathrm{CL}$, et al. A model to predict survival in patients with end-stage liver disease. Hepatology 2001; 33:464-470.

26 Jeong IB, Lee TH, Lim SM, Ryu KH, Kim YS, Kim SM, et al. Endoscopic findings and clinical significance of portal hypertensive colopathy. Korean $\mathrm{J}$ Gastroenterol 2011; 58:332-337.

27 Murphy SF, Durand M, McMorrow JP, Meaney JF, Guiney M. Portal hypertensive colopathy with pelvic varices presenting as severe lower Gl bleed treated with TIPSS. Ir Med J 2018; 111:696.

28 Jeon SR, Kim JO. Capsule endoscopy for portal hypertensive enteropathy. Gastroenterol Res Pract 2016; 2016:8501394.

29 Rondonotti E, Villa F, Signorelli C, de Franchis R. Portal hypertensive enteropathy. Gastrointest Endosc Clin N Am 2006; 16:277-286.

30 Gupta R, Saraswat VA, Kumar M, Naik SR, Pandey R. Frequency and factors influencing portal hypertensive gastropathy and duodenopathy in cirrhotic portal hypertension. J Gastroenterol Hepatol 1996; 11:728-733.

31 Thuluvath PJ, Yoo HY. Portal hypertensive gastropathy. Am J Gastroenterol 2002; 97:2973-2978.

32 Hosking SW, Kennedy HJ, Seddon I, Triger DR. The role of propranolol in congestive gastropathy of portal hypertension. Hepatology 1987; 7:437-441.

33 Branco JC, Carvalho R, Alberto SF, Reis J. Long-acting octreotide is effective in the treatment of portal hypertensive colopathy. Gastroenterol Hepatol 2017; 40:536-537. 